\title{
Enhanced oil recovery after polymer flooding by wettability alteration to gas wetness using numerical simulation
}

\author{
Kewen $\mathrm{Li}^{1,2,3, *}$, Changhui Cheng ${ }^{4}$, Changwei Liu ${ }^{1}$, and Lin Jia ${ }^{1}$ \\ ${ }^{1}$ School of Energy Resources, China University of Geosciences (Beijing), 29 Xueyuan Road, Beijing 100083, China \\ ${ }^{2}$ Key Laboratory of Marine Reservoir Evolution and Hydrocarbon Enrichment Mechanism, Ministry of Education, \\ Beijing 100083, China \\ ${ }^{3}$ Department of Energy Resources Engineering, Stanford University, Stanford, CA 94305, USA \\ 4 Jianghan Oilfield Branch, Sinopec, Beijing 100728, China
}

Received: 22 December 2017 / Accepted: 28 June 2018

\begin{abstract}
Polymer flooding, as one of the Enhanced Oil Recovery (EOR) methods, has been adopted in many oilfields in China and some other countries. Over $50 \%$ oil remains undeveloped in many oil reservoirs after polymer flooding. It has been a great challenge to find approaches to further enhancing oil recovery when polymer flooding is over. In this study, a new method was proposed to increase oil production using gas flooding with wettability alteration to gas wetness when polymer flooding has been completed. The rock wettability was altered from liquid- to gas wetness during gas flooding. An artificial oil reservoir was constructed and many numerical simulations have been conducted to test the effect of wettability alteration on the oil recovery in reservoirs developed by water flooding and followed by polymer flooding. Production data from different scenarios, water flooding, polymer flooding after water flooding, gas flooding with and without wettability alteration after polymer flooding, were calculated using numerical simulation. The results demonstrate that the wettability alteration to gas wetness after polymer flooding can significantly enhance oil recovery and reduce water cut effectively. Also studied were the combined effects of wettability alteration and reservoir permeability on oil recovery.
\end{abstract}

\section{Nomenclature}

$k_{\text {rnw }} \quad$ Relative permeability of nonwetting phase

$k_{\mathrm{rw}} \quad$ Relative permeability of wetting phase

$k_{x} \quad$ Absolute permeability of the reservoir in $X$ direction

$k_{y} \quad$ Absolute permeability of the reservoir in $Y$ direction

$k_{z} \quad$ Absolute permeability of the reservoir in $Z$ direction

$N X \quad$ Number of cells in $X$ direction

$N Y \quad$ Number of cells in $Y$ direction

$N Z \quad$ Number of cells in $Z$ direction

$P_{\text {cog }} \quad$ Oil-gas capillary pressure

$P_{\text {cow }}$ Oil-water capillary pressure

$P_{\text {cwg }}$ Gas-water capillary pressure

$S_{\mathrm{w}}^{*} \quad$ Normalized wetting phase saturation

$\lambda \quad$ Pore size distribution index

\section{Introduction}

Within the past decades, polymer flooding, as one of the Enhanced Oil Recovery (EOR) techniques, has been conducted successfully across many oil fields in the world. As early as 1972, Bondor et al. (1972) studied the effect of polymer flooding in complex reservoirs by mathematical simulation. Kazemi et al. (1976) developed a three-dimensional, multiple-well, numerical simulator for simulating single- or two-phase flow of water and oil for fractured reservoirs. Polymer flooding can yield a significant increase in oil recovery. Aluhwal and Kalifa (2008) researched the method of improving oil recovery by polymer flooding in a Malaysian reservoir. Hydrophobically associating polyacrylamide (HAPAM) is considered to be a promising candidate for polymer flooding, and many scholars have done some research work. Zhang et al. (2015) found under certain conditions, HAPAM can establish a higher resistance factor and residual resistance factor. Wang et al. (2002) studied the experiences after production of more than 300 million barrels of oil by polymer flooding in Daqing Oil Field. The oil recovery by polymer flooding was nearly $10 \%$ higher than

\footnotetext{
* Corresponding author: likewen@cugb.edu.cn
} 
that of water flooding for many reservoirs. Jennings et al. (1971) proposed Viscoelastic behavior provides a basis for a convenient measure of the mobility control activity of some polymers. Paul et al. (1982) survey on polymer flooding projects for a thorough evaluation of EOR methods. Needham and Doe (1987) focused on case histories where full-scale polymer floods were applied. Falode and Afolabi (2011) found that there is a gradual reduction in polymer adsorption with increase in reservoir brine hardness. Jamaloei et al. (2012) quantified the effect of viscous instability at varying salinities of the displacing non-wetting phase in the presence of the adverse mobility ratio. However, at the later production period of polymer flooding, the oil recovery was no longer increasing significantly. Furthermore, the residual oil distribution after polymer flooding was highly heterogeneous. Therefore, the further development of such reservoirs has become a big challenge due to high water cut, severe heterogeneity and highly dispersed residual oil.

Currently, the technique for enhancing oil recovery after polymer flooding is of practical importance to petroleum industry. In recent years, more attention has already been paid to this area. For instance, Cheng et al. (2010) evaluated the remaining oil distribution after polymer flooding. Dai et al. (2010) conducted the research on reutilization technology of residual polymer in formation after polymer flooding. Hou et al. (2012) proposed and investigated the foam flooding EOR technique after polymer flooding. Liu and Li (2011) conducted chemical analysis and physical simulation experiments to take charge of the residual polymer to conquer water breakthrough and enhance oil recovery after polymer flooding. Xie et al. (2009) conducted numerical simulation of oil recovery after cross-linked polymer flooding. Verga et al. (2017) used core-shell technology to help improve the effectiveness of waterflooding interventions. Valavanides (2018) used the DeProF true-to-mechanism theoretical framework to reveal the effects of underlying flow mechanisms in immiscible steady-state two-phase flow in porous media. However, these methods have their limitations to some extent and their effects of enhancing oil recovery are not quite significant. Therefore, it is worthy of searching for a good technique to enhance oil recovery after polymer flooding.

Some researchers carried out the experiments of wettability alteration to verify its effect on enhancing oil recovery. Lenormand et al. (1997) evaluated the effect of wettability and heterogeneity on oil recovery by numerical simulation. Murata (1981) proposed a method to estimate the coal wettability. Masalmeh (2003) studied wettability heterogeneity effects at the core or pore scale. Qiao et al. (2012) investigated the interfacial tension behaviors of a series of surfactants and the influencing factors of producing ultra-low interfacial tension. Zhang et al. (2006) studied the wettability alteration in chalk to help improve oil recovery. $\mathrm{Li}$ and Firoozabadi (2000) put forward the concept of wettability alteration to gas wetness and successfully altered the wettability of porous media from preferential liquid- to gas-wetting by using chemicals. Later, more attention has been paid to the effect of wettability alteration to gas wetness on oil and gas production. Li and Liu (2011) studied the method of enhancing gas-condensate
Table 1. Model parameters of the basic case.

\begin{tabular}{lll}
\hline Properties & Value & Unit \\
\hline$k_{x}$ & 100 & $\mathrm{mD}$ \\
$k_{y}$ & 100 & $\mathrm{mD}$ \\
$k_{z}$ & 10 & $\mathrm{mD}$ \\
Porosity & $12.8 \%$ & $/$ \\
Depth of top faces & 4000 & $\mathrm{ft}$ \\
Rock compressibility & $3 \times 10^{-6}$ & $/ \mathrm{psi}$ \\
Polymer concentration & 0.2 & $\mathrm{lb} / \mathrm{stb}$ \\
Oil viscosity & 3 & $\mathrm{cp}$ \\
Oil density & 52 & $\mathrm{lb} / \mathrm{ft}^{3}$ \\
Water density & 64 & $\mathrm{lb} / \mathrm{ft}^{3}$ \\
Gas density & 0.044 & $\mathrm{lb} / \mathrm{ft}^{3}$ \\
\hline
\end{tabular}

production by wettability alteration to gas wetness. Liu et al. (2006) conducted experiments in laboratory and improved production in gas reservoirs by wettability alteration to gas wetness. Su et al. (2010) found intermediate wettability is the most favorable to enhance oil recovery. Ma et al. (2011) conducted experiments for enhanced oil recovery with wettability alteration to gas wetness. Ren et al. (2008) expand the application of wettability reversal agent in low permeability and bottom water oil reservoir. In the field of numerical simulation, wettability is coupled with capillary pressure and relative permeability. Kou et al. (2010) studied the impact of capillary pressure on oil production by numerical simulation. According to current theoretical studies, wettability alteration has a positive effect on improving oil and gas production.

The oil recovery, as mentioned previously, was almost no longer increasing at the later production period of polymer flooding. One question arises: what other technologies could be utilized for EOR after polymer flooding? To answer this question, we propose the method of wettability alteration to gas wetness after polymer flooding in this paper. The process of gas flooding with wettability alteration after polymer flooding has been simulated by using a commercial software. The factors of affecting oil recovery have also been analyzed. The results demonstrate that wettability alteration could enhance oil recovery remarkably after polymer flooding.

\section{Theoretical background}

This research was to model the designed displacement processes with a professional numerical simulator, which is a commercial finite differences simulator widely used in the petroleum industry. All simulations were conducted using black oil model in the commercial software mentioned previously. The model has been kept as simple as possible: The grid was set up as a Cartesian grid $(N X=50, N Y=1, N Z=10)$. The size of the reservoir model was 750,75 , and 120 feet in the $x, y$, and $z$ directions respectively $(x=750 \mathrm{ft}, y=75 \mathrm{ft}$, $z=120 \mathrm{ft}$ ). Table 1 gives an overview of all important 


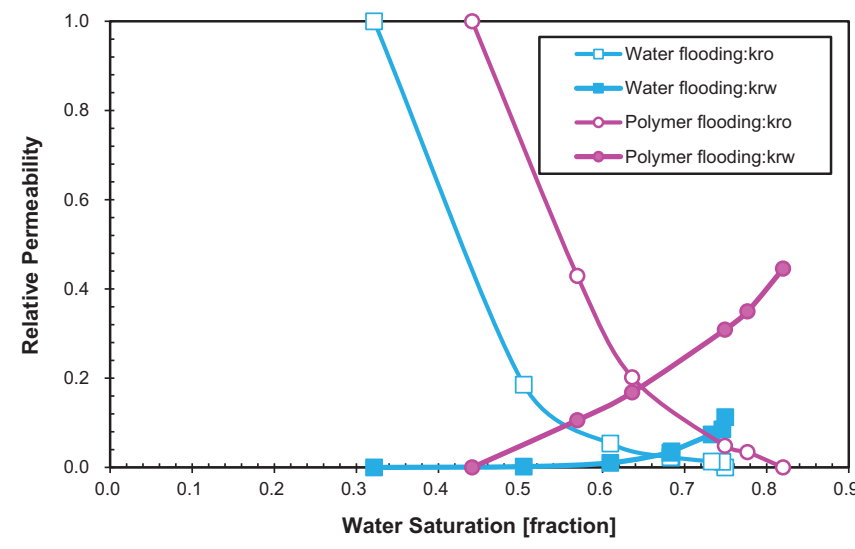

Fig. 1. Oil-water relative permeability of water flooding and polymer flooding.

parameters that have been used for the basic case. Other parameters, such as relative permeability and capillary pressure, are illustrated in Figures 1-4 respectively. The reservoir model was nearly homogeneous.

The oil-water and oil-polymer relative permeability data shown in Figure 1, including the capillary pressure data shown in Figure 2, were chosen and determined according to the experimental data obtained from the research associated with the paper by Li et al. (2014). It is reasonable that the residual oil saturation by polymer flooding was less than that by routine water flooding.

The capillary pressure data shown in Figure 3 and the relative permeability data shown in Figure 4 before and after wettability alteration were established based on the experimental data obtained from the research associated with papers (Li and Firoozabadi, 2000; Li and Horne, 2005).

During the simulation, the change in wettability of the rock was modeled by altering capillary pressure and relative permeability. In order to ensure the stability of initial pressure and saturation, equilibrium initializations of these parameters were used to define the initial state. End-point scaling option was active to define values for saturations in the saturation tables describing the flow of the reservoir fluids. The variation in the relative permeabilities of different displacement processes was considered. Figure 5 shows the geometry of the numerical model.

\section{Description and application of processes}

On the basis of above model, we compared the performance of four different displacement processes. The four processes, referred as to Case 1, Case 2, Case 3, and Case 4, are expressed respectively as follows:

Case 1: water flooding (6000 days);

Case 2: water flooding (1000 days) + polymer flooding (5000 days);

Case 3: water flooding (1000 days) + polymer flooding (2000 days) + gas flooding (3000 days);

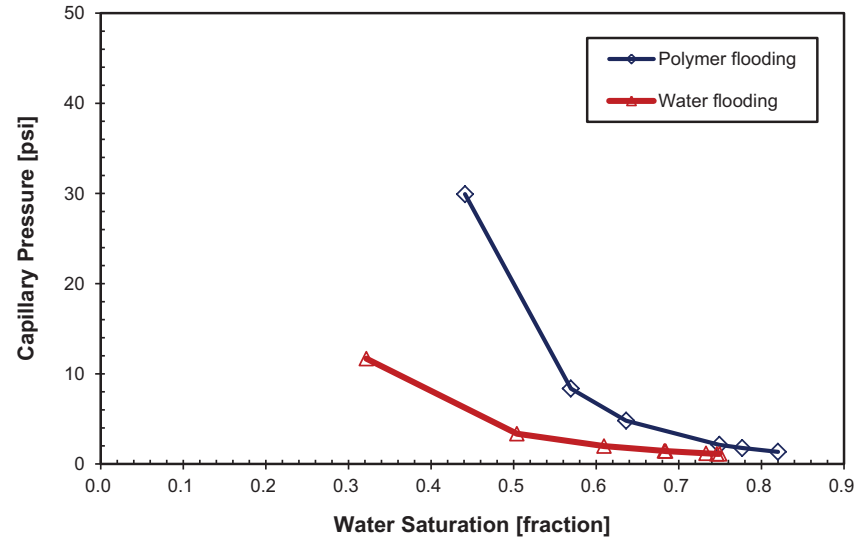

Fig. 2. Oil-water capillary pressure curve.

Case 4: water flooding (1000 days) + polymer flooding (2000 days) + gas flooding with wettability alteration to gas wetness (3000 days).

In the following sections, WF stands for water flooding, PF stands for polymer flooding, GF for gas flooding, and GFWA for the process of gas flooding with wettability alteration to gas wetness.

In order to verify the effect of oil-gas relative permeability (wettability) on production performance, we also compared production results of five different relative permeabilities. For comparison, we calculated five sets of oil-gas relative permeabilities by using the Brooks-Corey (1966) and Purcell (1949) model. The relative permeability data of nonwetting phase were determined with equation (1) and the relative permeability of wetting phase were computed with equation (2). The results are shown in Figure 6.

$$
k_{\mathrm{rw}}=\left(S_{\mathrm{w}}^{*}\right)^{\frac{2+\lambda}{\lambda}}(\text { Purcell, 1949), }
$$

$k_{\mathrm{rnw}}=\left(1-S_{\mathrm{w}}^{*}\right)^{2}\left[1-\left(S_{\mathrm{w}}^{*}\right)^{\frac{2+\lambda}{\lambda}}\right]($ Brooks and Corey, 1966).

Note that the reason for calculating the relative permeability data of nonwetting phase and the wetting phase was analyzed by Li and Horne (2006).

The capillary pressure curves before and after wettability alteration to gas wetness are shown in Figure 7. Other parameters remain constant.

\section{Presentation of data and results}

Numerical simulations were conducted using the above data. Note that the initial water saturations were $25 \%$ for the water flooding and constant flow rates were used. In this section, the results of the numerical simulation will be presented. In addition, the influential factors of the four processes will also be discussed. 


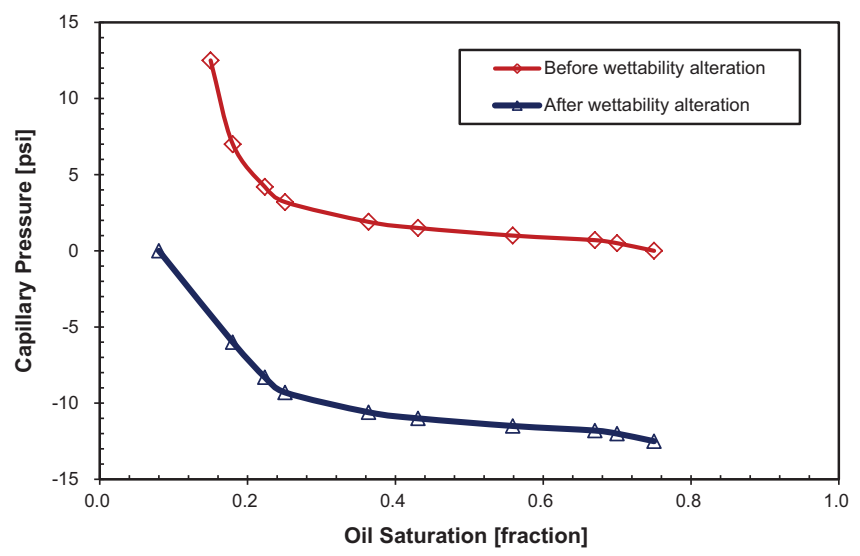

Fig. 3. Oil-gas capillary pressure curve before and after the wettability alteration to gas-wetness.

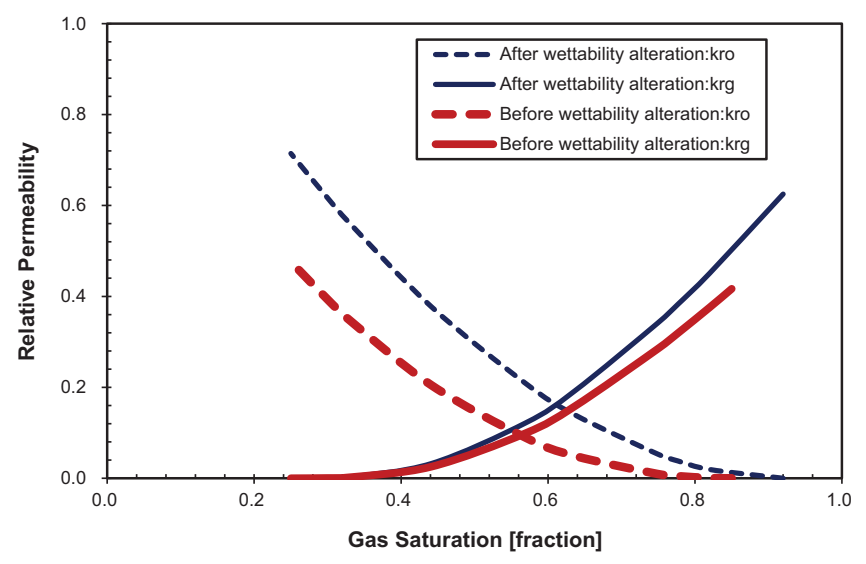

Fig. 4. Oil-gas relative permeability before and after the wettability alteration to gas-wetness.

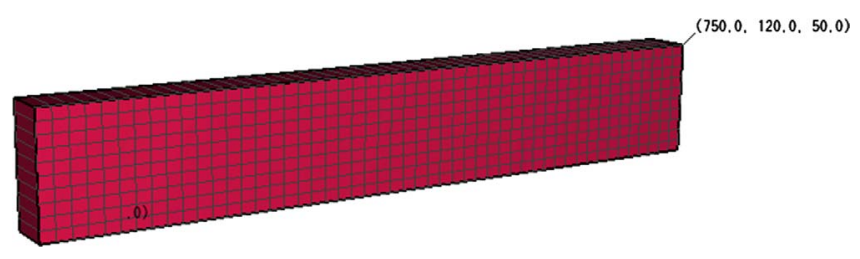

Fig. 5. Geometry of the reservoir model.

\subsection{Comparison of four displacement processes}

Figure 8 illustrates the oil recovery of $\mathrm{WF}$ and $\mathrm{WF}+\mathrm{PF}$. A polymer slug was injected into the reservoir after water flooding for 1000 days. As expected, the effect of polymer flooding is significant. Oil recovery with PF increases by more than 10\%. Comparing with the process without injecting polymer, it has higher oil production and lower water cut, which means polymer flooding can effectively reduce mobility ratio of water-oil, and ultimately enhance oil recovery.

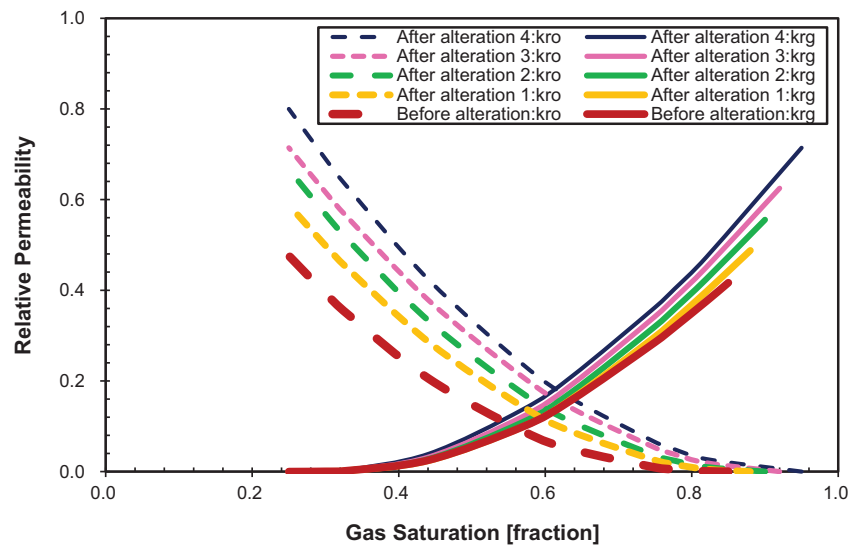

Fig. 6. Oil-gas relative permeabilities before and after wettability alteration to gas wetness.

Oil recovery and oil production rate of the designed four displacement processes are illustrated in Figures 9 and 10, respectively. The effects of polymer flooding and gas flooding on oil recovery are obvious, as shown in Figure 9. Ultimate oil recovery of the process with wettability alteration $(\mathrm{WF}+\mathrm{PF}+\mathrm{GFWA})$ is more than $80 \%$, which is much greater than that of the other three processes. Figure 10 shows the oil production rates of the four processes. It can be seen that oil production rates of the two processes with gas flooding ( $\mathrm{WF}+\mathrm{PF}+\mathrm{GF}$ and $\mathrm{WF}+\mathrm{PF}+\mathrm{GFWA})$ increase swiftly in the early period, especially the process with wettability alteration to gas wetness (WF $+\mathrm{PF}+\mathrm{GFWA}$ ). The highest rate is up to about $25 \mathrm{stb} /$ day. While at the later period, the oil production rates of gas flooding $(\mathrm{WF}+\mathrm{PF}+\mathrm{GF}$ and $\mathrm{WF}+\mathrm{PF}+\mathrm{GFWA})$ decrease sharply, and the differences among the four processes become smaller as well.

One can see from the above results that both gas flooding with and without wettability alteration after polymer flooding increase oil recovery effectively, especially the process with wettability alteration to gas wetness. Besides, the oil production rate increases significantly as well. Due to the wettability altered from preferential liquid-wetting to preferential gas-wetting, capillary pressure may become the driving force of gas flow, and the gas phase, as the wetting phase, may occupy the area closer to the rock surface. This may eventually improve the production performance after polymer flooding.

\subsection{Production performance of different oil-gas relative permeabilities}

In this section, we present the oil production results using five different sets of relative permeability curves. The results, from numerical simulation, include oil recovery, cumulative liquid production and oil production rate, as shown in Figures 11-13.

We can see from Figure 11 that the effect of relative permeability (wettability) on production performance is significant. With the increasing of relative permeability, i.e., wettability is altered from preferential liquid-wetting to 


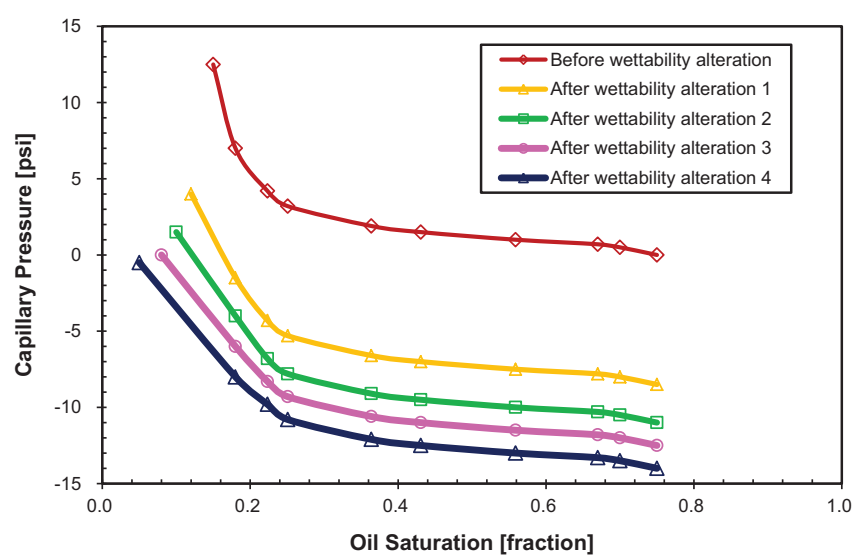

Fig. 7. Oil-gas capillary pressure before and after wettability alteration to gas wetness.

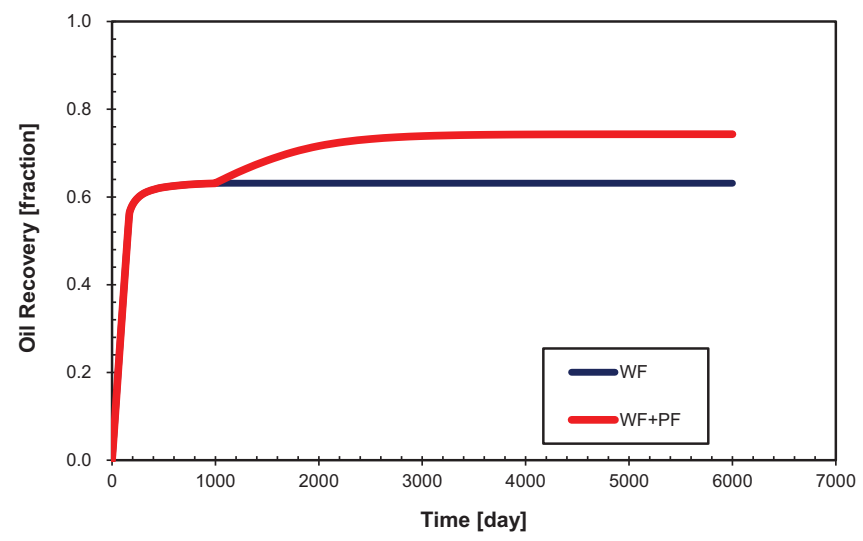

Fig. 8. Oil recovery of Project (1) and (2).

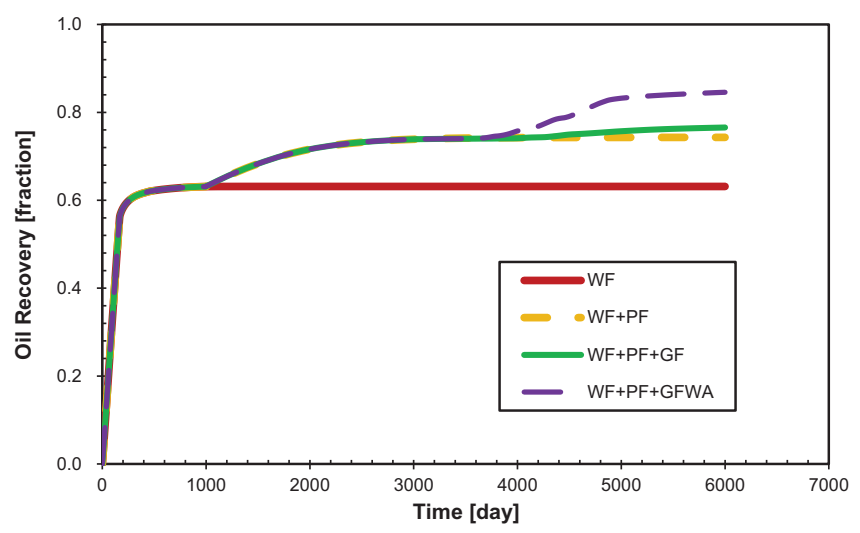

Fig. 9. Oil recovery of Project (1), (2), (3) and (4).

preferential gas-wetting, oil recovery is gradually enhanced. The highest final recovery with wettability alteration is about $15 \%$ over the recovery without wettability alteration.

Figure 12 shows the oil production rates of the five different sets of relative permeabilities. It can be seen that the

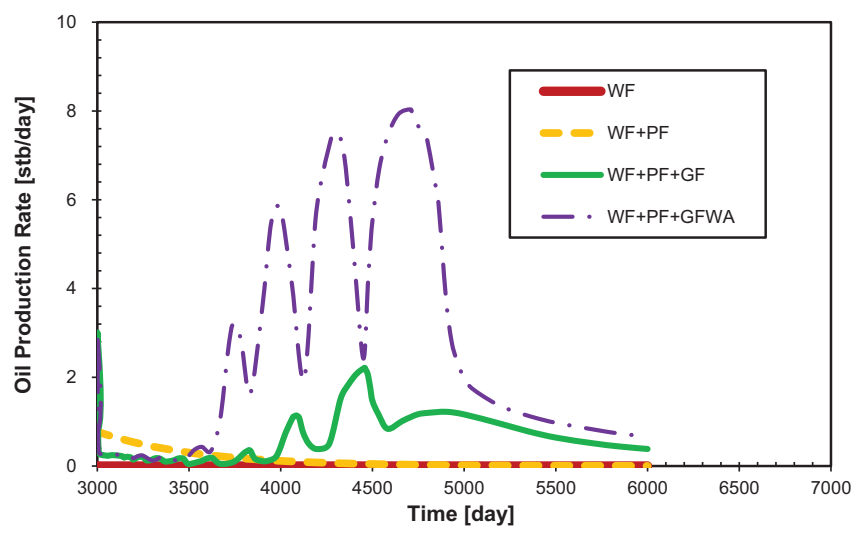

Fig. 10. Oil production rate after polymer flooding.

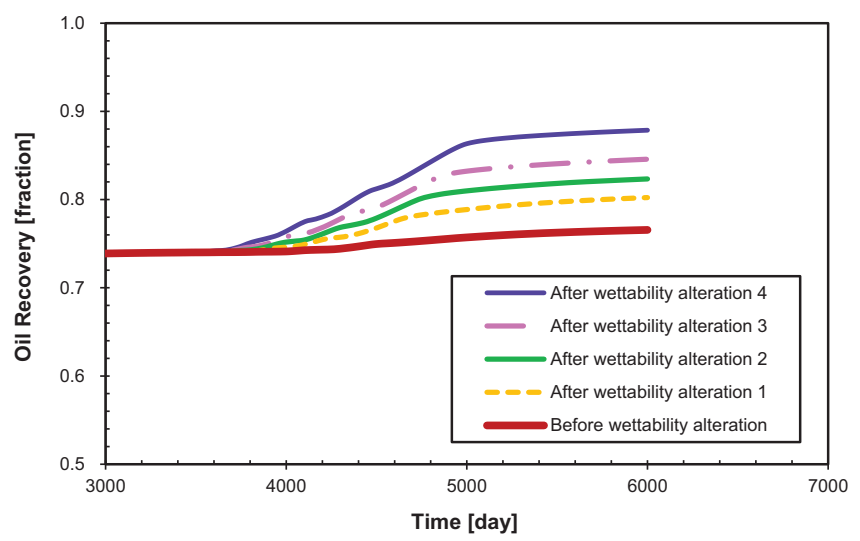

Fig. 11. Comparison of oil recoveries with different oil-gas relative permeabilities.

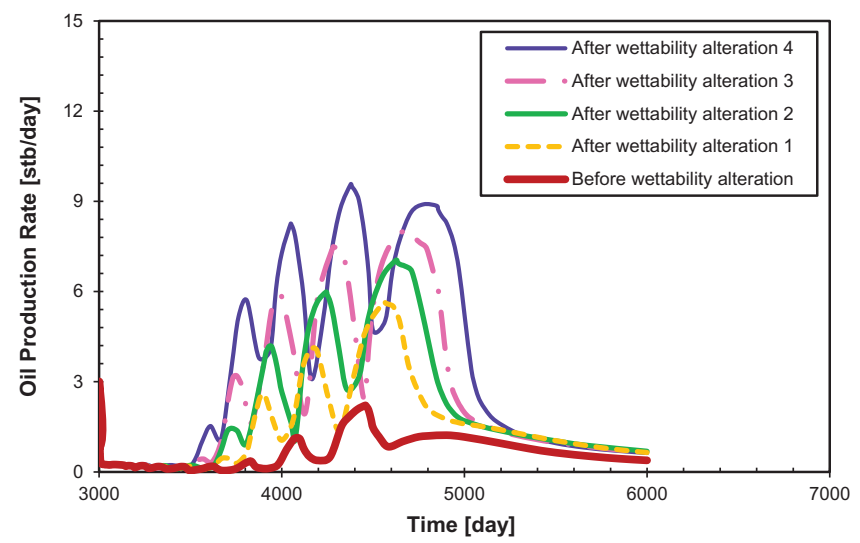

Fig. 12. Comparison of oil production rates with different oilgas relative permeabilities.

oil production rates increase obviously after wettability alteration to gas wetness. The stronger the preferential gas-wetting of rock wettability, the more swiftly the oil production rates increase. At the later period, oil production 


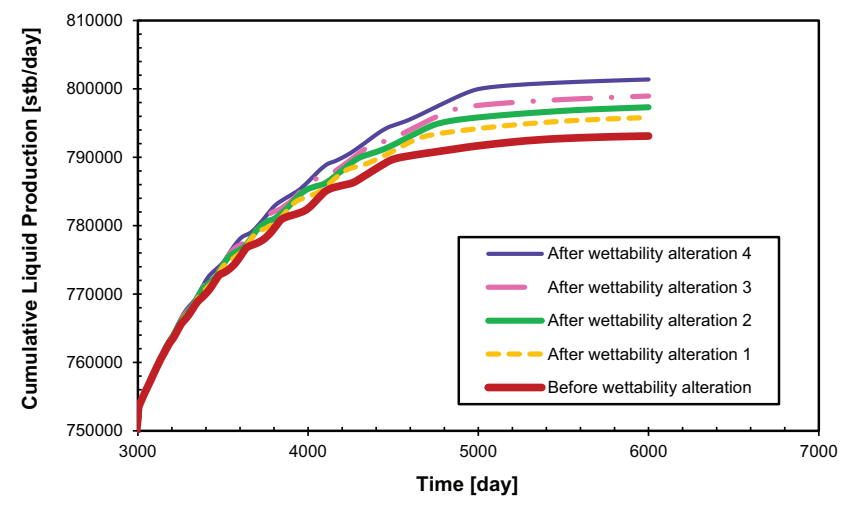

Fig. 13. Comparison of cumulative liquid production with different oil-gas relative permeabilities.

Table 2. Reservoir permeability data.

\begin{tabular}{lccc}
\hline \multicolumn{4}{c}{ Reservoir permeability } \\
\hline No. & $k_{x}(\mathrm{mD})$ & $k_{y}(\mathrm{mD})$ & $k_{z}(\mathrm{mD})$ \\
\hline 1 & 100 & 100 & 10 \\
2 & 200 & 200 & 20 \\
3 & 500 & 500 & 50 \\
4 & 1000 & 1000 & 100 \\
5 & 2000 & 2000 & 200 \\
\hline
\end{tabular}

rates begin to decrease, and the differences among the five sets become small.

Figure 13 demonstrates the cumulative liquid production of the five sets of relative permeabilities. Considering the wettability altered from preferential liquid- to gas-wetting, capillary pressure becomes the resistance force for water flow. Therefore, water production decreases while the oil recovery increases, which explains the cumulative liquid production have less significant differences among the five sets of relative permeabilities.

As an overall outcome, it can be seen that the effect of wettability on production performance is significant, and wettability alteration from liquid- to gas-wetness can effectively enhance oil recovery. The gas flooding with wettability alteration after polymer flooding can help reduce water cut and improve well deliverability.

\subsection{Sensitivity analysis of the reservoir permeability}

In this section, we conducted sensitivity analysis of permeability. Oil recoveries for five different permeabilities were compared. Table 2 illustrates the data of reservoir permeabilities. The oil recoveries for different permeabilities with and without wettability alteration are shown in Figures 14 and 15 .

One can see from Figures 14 and 15 that the oil recoveries increase with the reservoir permeabilities but not significantly. The results demonstrate that the effect of

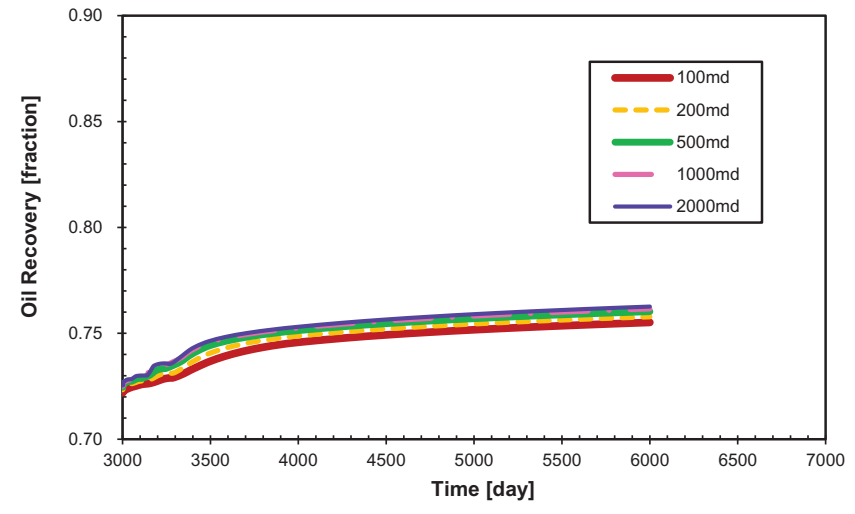

Fig. 14. Oil recoveries for different reservoir permeabilities without wettability alteration to gas wetness.

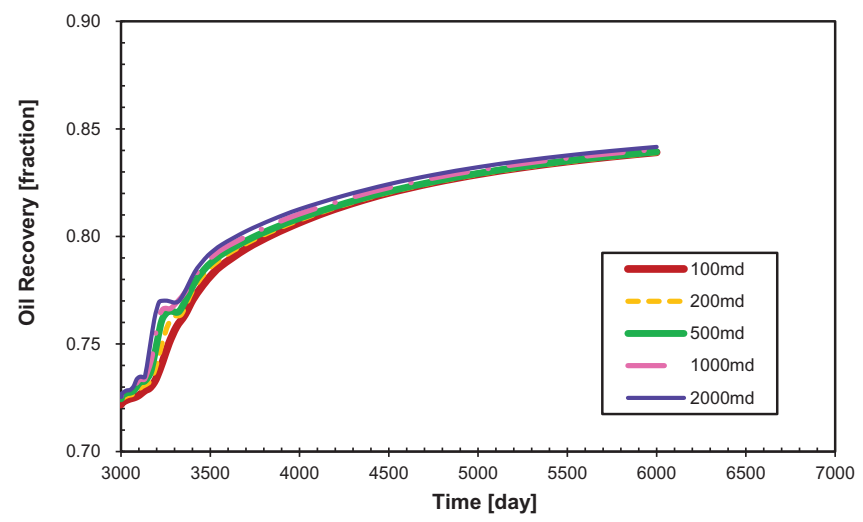

Fig. 15. Oil recoveries for different reservoir permeabilities with wettability alteration to gas wetness.

permeability on oil recovery is relatively small, especially after wettability alteration. Note that whatever permeability it is, the increase in oil recovery with wettability alteration is similar, which implies that permeability may not change the effect of wettability alteration on oil recovery.

\section{Conclusion}

The following conclusions may be drawn according to the results obtained in the present study:

- The oil recovery by gas flooding with wettability alteration to gas-wetness after polymer flooding could be increased about $10 \%$.

- The effect of permeability on oil recovery is relatively small in different cases in which wettability was changed to gas wetness.

- Considering the effect of wettability on production performance and the high water-cut situation, gas flooding with wettability alteration to gas wetness after polymer flooding may be a good choice for oil reservoirs currently under polymer flooding. 


\section{References}

Aluhwal H., Kalifa O. (2008) Simulation study of improving oil recovery by polymer flooding in a Malaysian reservoir, Master's Thesis, Faculty of Chemical and Natural Resources Engineering, Universiti Teknologi Malaysia.

Bondor P.L., Hirasaki G.J., Tham M.J. (1972) Mathematical simulation of polymer flooding in complex reservoirs, $S P E J$. 12, 5, 369-382.

Brooks R.H., Corey A.T. (1966) Properties of porous media affecting fluid flow, J. Irrig. Drain. Div. 6, 61.

Cheng J., Wei J., Song K., Han P. (2010) Study on remaining oil distribution after polymer flooding, in SPE Annual Technical Conference and Exhibition, Florence, Italy, September 19-22.

Dai C., You Q., Wang Y., Zhao F., Shuler P. (2010) Research on reutilization technology of residual polymer in formation after polymer flooding, in SPE Improved Oil Recovery Symposium Tulsa, OK, USA, April 24-28.

Falode O.A., Afolabi F.A. (2011) Simulation study of polymer flooding performance: effect of clay minerals, Petrol. Coal 53, 3, 206-211.

Hou Q., Zhu Y., Luo Y., Weng R. (2012) Studies on foam flooding EOR technique for Daqing Reservoirs after polymer flooding, in SPE Improved Oil Recovery Symposium, Tulsa, OK, USA, April, 14-18.

Jamaloei B.Y., Kharrat R., Asghari K. (2012) The influence of salinity on the viscous instability in viscous-modified lowinterfacial tension flow during surfactant-polymer flooding in heavy oil reservoirs, Fuel 97, 174-185.

Jennings R.R., Rogers J.H., West T.J. (1971) Factors influencing mobility control by polymer solutions, J. Petrol. Technol. 23, 3, 391-401.

Kazemi H., Merrill L.S. Jr, Porterfield K.L., Zeman P.R. (1976) Numerical simulation of water-oil flow in naturally fractured reservoirs, SPE J. 16, 6, 317-326.

Kou X., Li Z., Wang R., Guo L. (2010) The study of the impact of capillary pressure curve on numerical simulation of gas field, OGSE 29, 9, 31-33 [in Chinese].

Lenormand R., Li K., Robin M., Codreanu D.B. (1997) Numerical evaluation of the combined effect of wettability and heterogeneity on waterflood performance, in Proc. of the 9th European Symposium on Improved Oil recovery, EAGE, The Hague, The Netherlands, October, 20-22.

Li K., Firoozabadi A. (2000) Experimental study of wettability alteration to preferential gas-wetting in porous media and its effects, SPE Reserv. Eval. Eng. 3, 2, 139-149.

Li K., Horne R.N. (2005) Computation of capillary pressure and global mobility from spontaneous water imbibition into oilsaturated rock, SPE J. 10, 4, 458-465.

Li K., Horne R.N. (2006) Comparison of methods to calculate relative permeability from capillary pressure in consolidated water-wet porous media, Water Resour. Res. 42, W06405.

Li K., Liu Y. (2011) Enhanced gas-condensate production by wettability alteration to gas wetness, J. Petrol. Sci. Eng. 78, 505-509.

Li K., Sun W., Li F., Qu Y., Yang Y. (2014) Novel method for characterizing single-phase polymer flooding, SPE J., 19, 19, 695-702, https://doi.org/10.2118/152988-PA.
Liu H., Li G. (2011) An enhanced oil recovery technology continually after polymer-flooding, in SPE Enhanced Oil Recovery Conference, Kuala Lumpur, Malaysia, July 19-21.

Liu Y., Zheng H., Huang G., Li G., Li K. (2006) Improving production in gas-condensate reservoirs by wettability alteration to gas wetness, in Presented at the $2006 \mathrm{SPE} / \mathrm{DOE}$ Symposium on Improved Oil Recovery, Tulsa, OK, USA, April 22-26, SPE 99739.

Ma D., Dong M., Si Z., Han C., Zhang L., Zeng M. (2011) Experimental study on enhanced oil recovery with wettability alteration to gas wetness, Fault-Block Oil and Gas Field 18, 3, 386-388 [in Chinese].

Masalmeh S.K. (2003) The effect of wettability heterogeneity on capillary pressure and relative permeability, J. Petrol. Sci. Eng. 39, 3-4, 399-408.

Murata T. (1981) Wettability of coal estimated from the contact angle, Fuel 60, 8, 744-746.

Needham R.B., Doe P.H. (1987) Polymer flooding review, J. Petrol. Technol. 39, 12, 1503-1507.

Paul G.W., Lake L.W., Pope G.A., Young G.B. (1982) A simplified predictive model for micellar-polymer flooding, in SPE California Regional Meeting, San Francisco, CA, USA, March 24-26.

Purcell W.R. (1949) Capillary pressures - Their measurement using mercury and the calculation of permeability, Trans. AIME 186, 39.

Qiao W., Li J., Zhu Y., Cai H. (2012) Interfacial tension behavior of double long-chain 1,3,5-triazine surfactants for enhanced oil recovery, Fuel 96, 220-225.

Ren X., Liu B., Li Y. (2008) Application of wettability reversal agent in low permeability and bottom water oil reservoir, FaultBlock Oil and Gas Field 15, 5, 72-74 [in Chinese].

$\mathrm{Su}$ H., Wu X., Li W. (2010) The effect of change of reservoir wettability on oil recovery, Petrol. Drill. Tech. 38, 6, 92-94.

Valavanides M.S. (2018) Oil fragmentation, interfacial surface transport and flow structure maps for two-phase flow in model pore networks. Predictions based on extensive, DeProF model simulations, Oil Gas Sci. Technol. - Rev. IFP Energies nouvelles $\mathbf{7 3}, 6$.

Verga F., Lombardi M., Maddinelli G., et al. (2017) Introducing core-shell technology for conformance control, Oil Gas Sci. Technol. - Rev. IFP Energies nouvelles 72, 1, 5.

Wang D., Cheng J., Wu J., Wang G. (2002) Experiences learned after production of more than 300 million barrels of oil by polymer flooding in Daqing Oil Field, in SPE Annual Technical Conference and Exhibition, San Antonio, TX, USA, September 29-October 2.

Xie C., Guan Z., Blunt M., Zhou H. (2009) Numerical simulation of oil recovery after cross-linked polymer flooding, J. Can. Petrol. Technol. 48, 4, 37-41.

Zhang P., Tweheyo M.T., Austad T. (2006) Wettability alteration and improved oil recovery in chalk: the effect of calcium in the presence of sulfate, Energy Fuels 20, 5, 2056-2062.

Zhang P., Wang Y., Yang Y., et al. (2015) Effective viscosity in porous media and applicable limitations for polymer flooding of an associative polymer, Oil Gas Sci. Technol. - Rev. IFP Energies nouvelles 70, 6, 931-939. 